\title{
$\frac{25}{1-24-80}$
}

th. 576

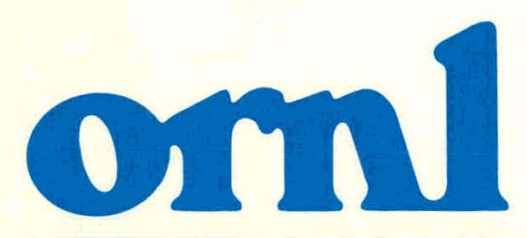

OAK

RIDGE

NATIONAL

LABORATORY

\section{Deuterium and Tritium Fueling in an ETF/INTOR Plasma with Divertor}

\author{
W. A. Houlberg \\ H. C. Howe \\ S. E. Attenberger
}

OPERATED BY

UNION CARBIDE CORPORATION FOR THE UNITED STATES DEPARTMENT OF ENERGY 


\section{DISCLAIMER}

This report was prepared as an account of work sponsored by an agency of the United States Government. Neither the United States Government nor any agency Thereof, nor any of their employees, makes any warranty, express or implied, or assumes any legal liability or responsibility for the accuracy, completeness, or usefulness of any information, apparatus, product, or process disclosed, or represents that its use would not infringe privately owned rights. Reference herein to any specific commercial product, process, or service by trade name, trademark, manufacturer, or otherwise does not necessarily constitute or imply its endorsement, recommendation, or favoring by the United States Government or any agency thereof. The views and opinions of authors expressed herein do not necessarily state or reflect those of the United States Government or any agency thereof. 


\section{DISCLAIMER}

Portions of this document may be illegible in electronic image products. Images are produced from the best available original document. 
Printed in the United States of America. Available from National Technical Information Service

U.S. Department of Commerce

5285 Port Royal Road, Springfield, Virginia 22161

NTIS price codes-Printed Copy: A03; Microfiche A01

This report was prepared as an account of work sponsored by an agency of the United States Government. Neither the United States nor any agency thereof, nor any of their employees, makes any warranty, expressed or implied, or assumes any legal liability or responsibility for any third party's use or the results of such use of any information, apparatus, product or process disclosed in this report, or represents that its use by such third party would not infringe privately owned rights. 
ORNL/TM- 7124

Dist. Category UC-20 a, d, g

Contract No. W-7405-eng-26

FUSION ENERGY DIVISION

DEUTERIUM AND TRITIUM FUELING IN AN ETE/INTOR

PLASMA WITH DIVERTOR

W. A. Houlberg

H. C. Howe

S. E. Attenberger

Date Pubtished - January 1980

NOTICE This document contains information of a preliminary nature.

It is subject to revision or correction and therefore does not represent a final report.

Prepared by the

OAK RIDGE NATIONAL LABORATORY

Oak Ridge, Tennessee 37830

operated by

UNION CARBIDE CORPORATION

for the

DEPARTMENT OF ENERGY

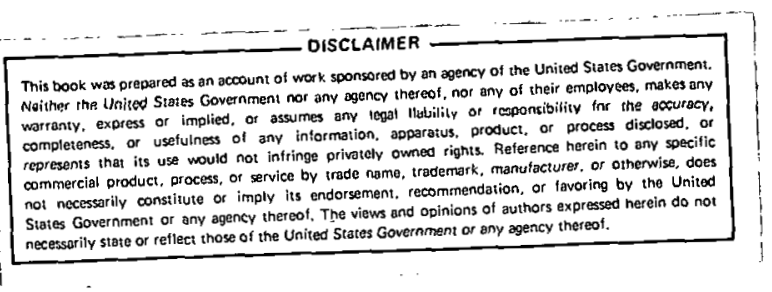




\section{THIS PAGE}

\section{WAS INTENTIONALLY \\ LEFT BLANK}




\section{CONTENTS}

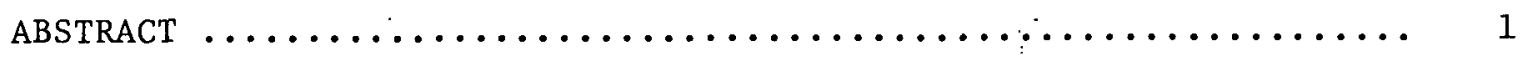

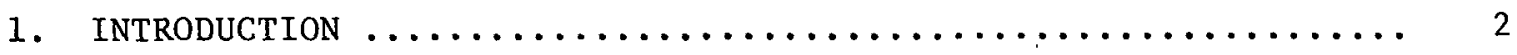

2. TRANSPORT MODELS FOR THE PLASMA AND SCRAPEOFF LAYER $\ldots \ldots \ldots \ldots .3$

3. PELLET AND GAS FUELING With A BUNDLE DIVERTOR $\ldots \ldots \ldots \ldots \ldots \ldots \ldots$

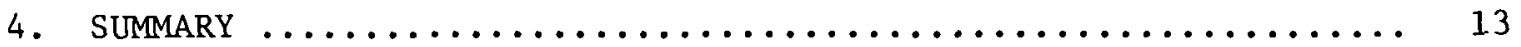

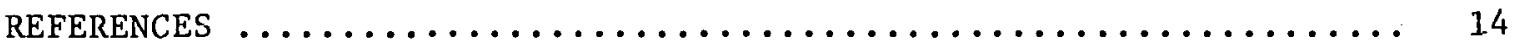


Fueling by pellets and neutral gas in the presence of a divertor is examined with a one-dimensional multispecies transport code. Deuterium, tritium, and alpha particles are treated as independent thermal species. With an efficiently operating divertor, it becomes impossible to maintain high plasma density $\left(\overline{\mathrm{n}} \sim 10^{14} \mathrm{~cm}^{-3}\right)$ with neutral gas fueling alone because of the high probability of the gas being ionized in the scrapeoff layer. Pellet fueling significantly reduces the particle load on the divertor and, with feedback control, can maintain the plasma density at the destred level. A low level of deuterium gas fueling can then be used to maintain the density of the scrapeoff layer and increase shielding against sputtered impurities. Even with an effective shielding divertor, the energy and particle fluxes to the first wall from both charged and neutral particles may be significant. The fluctuations at the plasma edge and in the scrapeoff layer introduced by the pellets cause the particle and energy fluxes to the divertor and first wall to fluctuate. This makes simulation more difficult but may be used to experimentally determine radial and parallel transport properties in the scrapeoff layer. Recommendations for further study are made. 


\section{INTRODUCTION}

The inclusion of a divertor/limiter region in transport modeling of tokamak plasmas is essential to understanding the distribution of particle and heat loads on the first wall and the limiter or divertor. ${ }^{1}$ The heat and particle loads in turn affect impurity production rates, wall damage from sputtering and blistering, heat removal requirements, and particle recycling. The divertor is meant to remove the interaction to a more remote area, i.e., a divertor chamber. In addition, the divertor should provide a means of pumplng hellum ash, of lunlzluy and pumping impurities in the scrapeoff layer before they reach the plasma, and of pumping impurities that diffuse from the plasma. A divertor, however, whether poloidal or bundle, has a large impact on the design of a system simply because space must be provided for the coils and divertor chamber. If the divertor is efficient at pumping impurities and helium ash, it will also certainly pump hydrogenic species and make refueling more difficult. This is the primary area of emphasis in this study. We use a bundle divertor model in an Engineering Test Facility/International Tokamak Reactor (ETF/INTOR) plasma to illustrate our approach to the problem. We point out some major uncertainties in the physics and indicate where our models can be improved with experimental and theoretical information. 
3

2. TRANSPORT MODELS FOR THE PLASMA AND SCRAPEOFF LAYER

The transport model in the WHIST code consists of a one-dimensional treatment of the ion particle balance equations coupled with electron and ion energy balances. In the present calculation, we include deuterium, tritium, and thermal alphas as separate species with a common Maxwellian temperature. Diverter terms are treated as sink terms in the scrapeoff region using the model of Manse and Emmet. ${ }^{l}$ The multispecies particle and energy balance equations are

$$
\begin{aligned}
& \frac{\partial n_{j}}{\partial t}=-\vec{\nabla}_{\perp} \cdot \vec{\Gamma}_{\perp j}-\vec{\nabla}_{\|} \cdot \vec{\Gamma}_{\| j}+s_{j}, \\
& \frac{\partial}{\partial t}\left(\sum_{j} \frac{3}{2} n_{j} T_{i}\right)=\sum_{j}\left[-\vec{\nabla}_{\perp} \cdot\left(\vec{Q}_{1 j}+\frac{3}{2} T_{1} \vec{\Gamma}_{\perp j}\right)-\vec{\nabla}_{\|} \cdot \vec{Q}_{\| j}+E_{j}\right],
\end{aligned}
$$

and

$$
\frac{\partial}{\partial t}\left(\frac{3}{2} \mathfrak{n}_{e} \cdot T_{e}\right)=-\vec{\nabla}_{\perp} \cdot\left(\vec{Q}_{\perp e}+\frac{3}{2} T_{e} \vec{\Gamma}_{\perp e}\right)-\vec{\nabla}_{\|} \cdot \vec{Q}_{\| e}+E_{e} \cdot
$$

These are subject to the charge neutrality constraints

$$
\begin{gathered}
\mathrm{n}_{e}=\sum_{j} z_{j} \mathrm{n}_{j}, \\
\vec{\Gamma}_{\perp e}=\sum_{j} z_{j} \vec{\Gamma}_{\perp j},
\end{gathered}
$$

and

$$
\vec{\Gamma}_{\| e}=\sum_{j} z_{j} \vec{\Gamma}_{\| j}
$$

0 
where the indices $j, e, \perp$, and $\|$ represent ion and electron species, radial and parallel flows, respectively. In Eq. (1), $\mathrm{s}_{j}$ represents all particle source terms for ion species $j$, and $E_{j}$ and $E_{e}$ represent net energy sources or losses for ion species $j$ and electrons. Particle sources from neutral gas are treated as continuous in time, using a neutral transport routine, i.e., with a multispecies version of SPUDNUT. ${ }^{2}$ Peilets are treated as sources of ions on a time scale that is short compared to all transport and radiative time scales. This is done by setting all terms on the right in Eqs. (1)-(3) to zero except for the particle source from pellets and the electron energy loss associated with ionization of the particles in the pellet. The equations are then time-integrated to give instantaneous changes in the densities and temperatures. ${ }^{3}$ For example, in the density equations,

$$
\int_{t}^{t} p_{p}^{+\varepsilon} d t\left[\frac{\partial n_{j}(r, t)}{\partial t}=s_{j}^{P}(r, t)\right]
$$

and

$$
{ }_{11}\left(r, L_{p}+\varepsilon\right)-n_{j}\left(r, t_{p}\right)=\Delta n_{j}^{T}(r),
$$

where $t_{p}$ represents the time of pellet injection and $\varepsilon$ is the time for complete ablation and ionization of the pellet (about $150 \mu \mathrm{sec}$ in our calculations).

The radial transport model in the plasma region consists of neoclassical transport ${ }^{4}$ plus ripple diffusion contributions to ion conduction, ${ }^{5}$ anomalous particle diffusion, and electron conduction:

$$
\begin{aligned}
& \Gamma_{\perp j}=\Gamma_{\perp j}^{\text {neo }}-D^{\text {an }} \frac{\partial n_{j}}{\partial r}, \\
& Q_{\perp j}=Q_{1 j}^{\text {neo }}-n_{j} x_{j}^{r i p} \frac{\partial T_{i}}{\partial r},
\end{aligned}
$$


and

$$
Q_{1 e}=Q_{1 e}^{\text {neo }}-n_{e} x_{e}^{\text {an }} \frac{\partial T e}{\partial r}
$$

where

$$
D^{\text {an }}=\frac{1.25 \times 10^{17}}{n_{e}}+5000\left(\frac{r}{r_{s}}\right)^{3}\left(\mathrm{~cm}^{2} / \mathrm{sec}\right)
$$

and

$$
x_{e}^{\text {an }}=\frac{1.0 \times 10^{17}}{n_{e}\left[1-0.4\left(\mathrm{r} / \mathrm{r}_{\mathrm{s}}\right)^{2}\right]^{3.5}}\left(\mathrm{~cm}^{2} / \mathrm{sec}\right)
$$

where $r_{s}$ represents the radius of the separatrix. The anomalous and ripple loss terms dominate the neoclassical values.

The toroidal field ripple is characterized by 12 coils with radial and poloidal variation in the ripple (peak to average) calculated from a specific toroidal field configuration:

$$
\delta(r, \theta)=\left\{\delta(0)+\left[\delta\left(r_{s}\right)-\delta(0)\right]\left(\frac{r}{r_{s}}\right)^{m}\right\} e^{-\beta \theta^{2}},
$$

where

$$
\begin{aligned}
\delta(0) & =0.0953 \%, \\
\delta\left(r_{s}\right) & =1.02 \%, \\
m & =2,
\end{aligned}
$$

and

$$
\beta=0.4 \text {. }
$$


All radial transport coefficients in the scrapeoff zone are taken to be Bohm:

$$
x_{e}=x_{i}=D=\frac{1}{16} \frac{T_{e}}{e B}
$$

Effective transport coefficients at the separatrix are determined from a flux continuity constraint, i.e.,

$$
\begin{aligned}
& \left.\Gamma_{j}\right|_{\text {plaoma }}=\left.I_{j}\right|_{\text {scrapeoff }} \equiv \Gamma_{j}, \\
& \Gamma_{j}=-D_{j}^{\text {eff }} \frac{\partial n_{j}}{\partial r}-D_{T}^{e f f} \frac{\partial T_{e}}{\partial r}-D_{T_{i}}^{\text {eff }} \frac{\partial T_{i}}{\partial r}-\sum_{i \neq j} D_{i}^{\text {eff }} \frac{\partial n_{i}}{\partial r}-D_{P}^{e f f} E_{\|} .
\end{aligned}
$$

A11 the "off-diagonal" terms in Eq. (5) (all terms other than the first term) typically come from the neoclassical model for the plasma. When a diagonal model such as ours is used in the scrapeoff zone, only the diagonal term appears at the separatrix:

$$
D_{j}^{\text {eff }}=2 \frac{D_{j}^{P_{D}^{S O}}}{D_{j}^{P}+D_{j}^{S O}},
$$

where $P$ and So superscripts reter to evaluations in the plastld and scrapeoff, respectively.

The parallel flow terms are those of Ref. 1 with generalizations for multiple ion species:

$$
-\vec{\nabla} \cdot \vec{\Gamma}_{\| j} \cong-\frac{\Gamma_{\| j}}{L_{\|}}=-\frac{n_{j} v_{\| j}}{L_{\|}},
$$




$$
\begin{aligned}
& -\vec{\nabla} \cdot \vec{Q}_{\| j} \cong-\frac{Q_{\| j}}{L_{\|}}=-\frac{2 T_{i} \Gamma_{\| j}}{L_{\|}}, \\
& -\vec{\nabla} \cdot \vec{Q}_{\| e} \cong-\frac{Q_{\| e}}{L_{\|}}=-\frac{2 T_{e} \gamma_{e} \Gamma_{\| e}}{L_{\|}}, \\
& \nu_{\| j}=\sqrt{\frac{T_{i}}{2 \pi m_{j}}}, \\
& 2 L_{\|}=\frac{2 \pi R_{o}}{d_{i}},
\end{aligned}
$$

where $d_{i} \cong 0.1$ is used to represent the fraction of the flux surface intercepted by a bundle divertor on a single transit around the device in the toroidal direction. For our calculations, $\gamma_{e}$ is nearly constant at 22.9 . 


\section{PELLET AND GAS FUELING WITH A BUNDLE DIVERTOR}

We apply our modcl to a device with parameters characteristic of the U.S. ETF design and of the IAEA sponsored INTOR design. The device has a major radius, $R_{0}=4.8 \mathrm{~m}$; a minor radius to the separatrix in the midplane, $r_{s}=1.2 \mathrm{~m}$; a plasma elongation of 1.6 ; a toroidal field on axis, $B_{T o}=53 \mathrm{kG}$; and a toroidal plasma current, $I_{p}=4 \mathrm{MA}$. A scrapeoff layer of $10 \mathrm{~cm}$ is assumed between the separatrix and the first wall in the midplane. Figure 1 schematically shows the particle balance terms for the deuterium and trllium componenta. $\Lambda 11$ terms are rnnsidered in our present caiculations excepl llee wall and divortor reryrle tarms. These must be included to complcte the model, but a number of observations can be made even without the recycle terms.

A steady-state burn is reached by heating the plasma to ignition with neutral beams, then allowing the heating from fusion-produced alphas to raise the temperature to a stable theruld eyuilibrium. $\Lambda$ relatively low-temperature thermal equilibrium is provided by the ripple conduction losses that dominate in the ion thermal balance. Figure 2 illustrates a typical pellet ablation profile during the burn. Essentially all of the pellet source is in the plastla region, but a rather small portion is still deposited ln the scrapeoff region. Separate pellets of deuterium and tritium are used in our calculations; each has a radius of $2 \mathrm{~mm}$ and a velocity of $2 \mathrm{~km} / \mathrm{sec}$. Every time the deuterium or tritium density drops below a volume average of $5 \times 10^{13} \mathrm{~cm}^{-3}$, a pellet of the appropriate species is injected. In practice, this would require separate detection of deuterium and tritium densities in the plasma and feedback to the pellet injectors. The pellets are falrly lalye lecausc thcy contain abnut $? \times 10^{21}$ particles. This is enough to raise the plasmd density by about $10^{13} \mathrm{~cm}^{-3}$, although the local density increase at the peak of the pellet ablation curve is above $5 \times 10^{13} \mathrm{~cm}^{-3}$. The pellets are treated as a local source of ions rather than as neutrals because the ISX pellet injection experiments seem to validate this assumption, 6,7 although a small contribution as neutrals cannot be ruled out. 
In general, it may be desirable to provide some fueling with neutral gas for several reasons. Neutral gas fueling increases the plasma density in the edge region, thereby reducing the plasma temperature and possibly the potential for sputtering. The density increase also increases the shielding efficiency of the divertor. However, we find in these calculations that at relatively low levels of neutral gas input, the divertor begins to shield out the hydrogenic species, and it becomes impossible to maintain a reasonably high plasma density. Under these circumstances, pellet fueling is essential. There are several factors that influence the maximum allowable gas input rate determined by the choking problem. In this case, the distance that the particles must flow along field lines to reach the divertor is quite long $\left(L_{\|} \cong 10 \pi R_{o}\right.$ for the bundle divertor); thus, parallel flow rates limit the pumping rate of the divertor. We have not included recycle from the divertor (determined by pumping rates in the divertor chamber) or recycle from the walls, 8 both of which would reduce the fueling requirements.

Figures 3 and 4 illustrate what happens as a deuterium gas source is introduced. In all cases, pellet injection is used to maintain the deuterium density when the gas source is insufficient. In Fig. 3, we show the final deposition of the deuterium neutrals as the cold gas source is increased. Time-averaged values of the net deuterium source in the plasma and scrapeoff layer and energetic fluxes of deuterium and tritium neutrals to the wall are shown. As the deuterium gas source is increased, the ratio of deuterium to tritium in the scrapeoff layer increases. This leads to a decreased probability of deuterium neutrals charge exchanging with tritium ions so that the fractional loss of tritium neutrals decreases and the fractional loss of deuterium neutrals increases. The fraction ionized is decreased slightly because the gas puffing lowers the edge temperature and charge exchange processes become more dominant. All of these cases are below the limit for choking in the divertor. In Fig. 4, we see that in addition to the neutral deuterium gas input, we require additional fueling by deuterium pellets to maintain the plasma density for the range of deuterium gas source considered. 
The deuterium pellet feed rate decreases as fueling is replaced by deuterium gas. The tritium pellet feed rate also decreases, even though there is an increased loss of tritium from charge exchange. This is because the deuterium gas cools the edge and the pellets penetrate further. Recycle of both deuterium and tritium from the wall would further reduce the required pellet feed rates.

The responses of the plasma and scrapeoff layer to pellet and gas fueling can be examined in more detail by taking a specific case. Here we will consider a case with tritium fueling with pellets only, a constant. neutral source of deuterium at $1.4 \times 10^{23} \mathrm{sec}^{-1}$, and addltional deuterium fueling with pellets to maintain the plasma deuterium density. The deuterium, tritium, and alpha densities are shown in Fig. 5 as a function of time for a 500-msec segment of steady-state operation for this case. Because of the pellet fueling, however, the plasma is never truly in steady state. The ion and electron temperature profiles at the end of this 500-msec simulation are shown in Fig. 6. The maximum temperatures at the separatrix before injection of a pellet are $2.5-3 \mathrm{keV}$ and drop to about half that value after injection of a pellet.

Pellet injection has a strong effect on the distribution of deuterium and tritium particle source and loss terms from deuterium gas putting. 'l'he volume-1ncegraced net surre Leims for the plasma and scrapeoff layer are shown as a function of time in Figs. 7 and 8 . There is a net loss of tritium in both the plasma and scrapeoff layer because of charge exchange losses. Immedlately after injection of a tritium peilet, there is an increase in the tritium denstty In the edge region from the immediate deposition and later from diffusion out of the plasma. This leads to an increased flux of neutral tritium to the wall, as shown in Fig. 9. Similarly, after injection of a deuterium pellet, there is an increase in the neutral flux of deuterium to the wall. After a pellet of either species is injected, the plasma density increases and the temperatures decrease as the particles distribute over the surface. 9,10 This leads to a decreased penetration of the neutrals and results in a lower source of deuterium in the plasma (Fig. 7) and an increased source in the scrapeoff layer (Fig. 8). 
The spatially integrated charged particle fluxes of deuterium and tritium to the divertor collector and the wall are shown in Figs. 10 and 11 , respectively. The models for parallel and radial flow have a strong influence on the relative fluxes to the divertor and wall and also on the time dependence of these terms. There is a rapid increase in the deuterium fluxes to both the wall and divertor immediately after a deuterium pellet is injected. These increases reflect the paralle1 and radial flow times. The same observation holds for tritium pellet injection. Cross coupling of the flow terms (e.g., effect of tritium pellet injection on deuterium fluxes) occurs because of the assumed temperature dependences of the radial and parallel transport. Experimental determination of these responses may provide further insight into transport in the scrapeoff layer.

The fluctuations introduced by the pellets dictate the time scales required for numerical simulation of the results. The transport equations in the divertor scrapeoff region are very stiff and can be solved with an implicit method, 11 as used here, or with the addition of several correctors in a predictor-corrector approach. 12 Because of the fluctuations introduced by the pellets, the neutral gas deposition and all interactions with the wall (e.g., reflectlon, sputtering, etc.) have to be updated frequently. This can make computations very time consuming unless fast, efficient models are developed. With the implicit treatment of the transport equations and the speed of the neutral calculations with SPUDNUT, ${ }^{2}$ we have managed to reduce computation time to 2 min nn the CDC 7600 for the $500 \mathrm{msec}$ of plasma simulation illustrated in Figs. 5-11. This allows us the time to extend the physics while still maintaining a useful tool for routine calculations.

Several areas of the model that are currently under development should provide a fairly complete picture of the plasma edge region and interactions with the wall. These areas include modifications to the divertor model, inclusion of recycle from the wall and divertor, sputtering of impurities, and transport of impurities in the scrapeoff layer. Modifications to the divertor model include the effects of secondary electron emission and finite ion temperatures on the sheath 
potential ${ }^{13}$ and mirroring in the bundle divertor throat. ${ }^{4}$ Existing experimental information from divertor experiments on DITE $^{15}$ and DIVA 16 and planned experiments on PDX, ASDEX, and ISX-B will help reduce the uncertainties in the parallel and radial transport models in the scrapeoff layer. Reflection of particles from the walls with the associated energy spectrum ${ }^{8}$ and a model for the buildup of hydrogenic species in the wall with eventual release of this gas ${ }^{17}$ are necessary for a full assessment of fueling and divertor pumping requirements. Recycle of particles from the divertor region is very dependent on the geometry of the divertor design and pumping capabllities. Some recycle of liydrugenit species from the divertor would actually be beneficial, provided the alpha particles and impurities are not also recycled. Finally, with all other parts of the model in place, an assessment can be made of the divertor's main purpose - its potential to reduce sputtering of impurities from the wall 17 and to pump those impurities that are released. To evaluate the divertor shielding capabilities, parallel flow terms are being added to a noncoronal radial transport model for impurities. 18 


\section{SUMMARY}

With an efficiently operating divertor, pellet fueling is necessary to fuel the plasma and reduce the particle load on the divertor. Some deuterium gas input can be used for additional control of the properties in the scrapeoff layer. Particle fluxes to the first wall can be significant but are sensitive to the model used for the divertor. A wider scrapeoff zone may be required for a bundle divertor than for a poloidal divertor because of the longer parallel flow length to the bundle divertor. This could be alleviated, however, with multiple bundle divertors. Pellet-induced fluctuations at the plasma edge make the transport analysis more difficult. Finally, further development of models is required before a full assessment of divertors and the scrapeoff layer can be made. 


\section{REFERENCES}

1. A. T. Mense and G. A. Emmert, Nucl. Fusion 19, 361 (1979).

2. K. Audenaerde, G. A. Emmert, and M. Gordinier, to be published in J. Comput. Phys. (Modified for multiple hydrogenic species by M. Gordinier.)

3. W. A. Houlberg, M. A. Iskra, H. C. Howe, and S. E. Attenberger, Oak Ridge National Laboratory Report ORNL/TM-6549, Oak Ridge, Tennessee $(19 / 9)$.

4. F. L. Ilinton and R. D. Hazeltine, Rev. Mod, Phys. 48, 239 (1976).

5. N. A. Uckan, T. Uckan, and J. R. Moore, Uak Rldge Nalivinal Laboratory Report ORNL/TM-5603, Oak Ridge, Tennessee (1976).

6. S. L. Milora, C. A. Foster, P. H. Edmonds, and G. L. Schmidt, Phys. Rev. Lett. 42, 97 (1979).

7. S. L. Milora, Bull. Am. Phys. Soc. 24,5 B3 (1979).

8. O. S. Oen and M. T. Robinson, Nuc1. Instrum. Methods 132,647 (1976).

9. A. T. Mense, W. A. Houlberg, S. E. Attenberger, and S. L. Milora, to be published in Nucl. Fusion 19 (1979).

10. D. F. Düchs, G. Haas, M. Keilhacker, K. Lackner, L. L. Lengye1, and C. T. Chang, Proc. 7th Int. Conf. on Flasma Prysuics and Controiled Nuclears Fusilur Feseirit, Vol. I, p. 315 (1978).

11. W. A. Houlberg and R. W. Conn, Nucl. Sci. Eng. 64, 141 (1977).

12. PROCTR, developed by H. C. Howe, Oak Ridge National Laboratory, Oak Ritge, Tennessee.

13. G. A. Emmert, R. M. Wieland, A. T. Mense, and J. N. Davidson, "The Electric Sheath and Presheath in a Collisionless, Finite Ion Temperature Plasma," submitted to Phys. Fluids.

14. $\Lambda$. Nicolai and A. T. Mense, Oak Kidge Nat1onal Laboratory RepurL ORNL/TM-6852, Oak Ridge, Tennessee (1979).

15. S. J. Fielding, M. Hobby, J. Hug111, G. M. McCracken, J. W. M. Pau1, N. J. Peacock, B. A. Powell, and P. E. Stott, Proc. 8th Finrop. Conf. on Controlled Fusion and Plasma Physics, Vo1. 1, p. 36 (1977); S. J. Fielding, J. W. M. Paul, and A. J. Wooten, to be published in Proc. 10th Europ. Conf. on Controlled Fusion and Plasma Physics (1979). 
16. DIVA Group, Nucl. Fusion 18, 1619 (1978); S. Segoku et al., J. Phys. Soc. Japan 45, 1385 (1978); Y. Shimomura and H. Maeda, J. Nuc1. Mater. $76 \& \underline{77}, 45$ (1978); H. Maeda et al., Proc. 7th Int. Conf. on Plasma Physics and Controlzed Nuclear Fusion Research, Vol. 1, p. 377 (1978).

17. G. M. McCracken and P. E. Stott, Nuc1. Fusion 19, 889 (1979).

18. E. C. Crume and D. E. Arnurius (Oak Ridge National Laboratory), private communication, 1979. 
Fig. 1. Schematic illustration of the particle balance equations for deuterium and tritium. $\Gamma$ and $S$ represent fluxes and volumetric sources, subscripts $D$ and $T$ represent deuterium and tritium, and superscripts 0 and + represent neutrals and ions. Additional superscripts of $\mathrm{p}, \mathrm{d}, \mathrm{s}, \mathrm{w}$, wr, and dr denote plasma, divertor, separatrix, wall, wall recycle, and divertor recycle terms, respectively.

Fig. 2. Typical pellet deposition profile showing penetration of the scrapeoff layer.

Fig. 3. Time-averaged deposition of deuterium in the plasma and scrapeoff zones and returned neutral fluxes as a function of the deuterium gas teed rate.

Fig. 4. Deuterium and tritium pellet fueling rates necessary to maintain densities of $\overline{\mathrm{n}}_{\mathrm{D}}=\overline{\mathrm{n}}_{\mathrm{T}}=5 \times 10^{13} \mathrm{~cm}^{-3}$ in the plasma as the gas source of deuterium is increased.

Fig. 5. Time dependence of the volume-averaged deuterium, tritium, and thermal alpha densities in the plasma. The increases in deuterium and tritium densities are due to pellet injection.

f'ig. 6. Eicctron and ion temperaturé profilés in thè plasma and scrapeoff layer.

Fig. 7. Volume-integrated net sources or losses of deuterium and tritium in the plasma from deuterium gas fueling.

Fig. 8. Volume-integrated net sources or losses of deuterium and tritium in the scrapeoff layer from deuterium gas fueling.

Fig. 9. Neutral fluxes of deuterium and tritium to the wall from deuterium gas fueling. Values are integrated over the entire wall.

Fig. 10. Charged particle fluxes of deuterium and tritium to the divertor collector integrated over the collector area.

Fig. 11. Charged particle fluxes of deuterium and tritium to the wall integrated over the entire wall. 


\section{PARTICLE BALANCES}

ORNL-DWG $79-3461$ FED

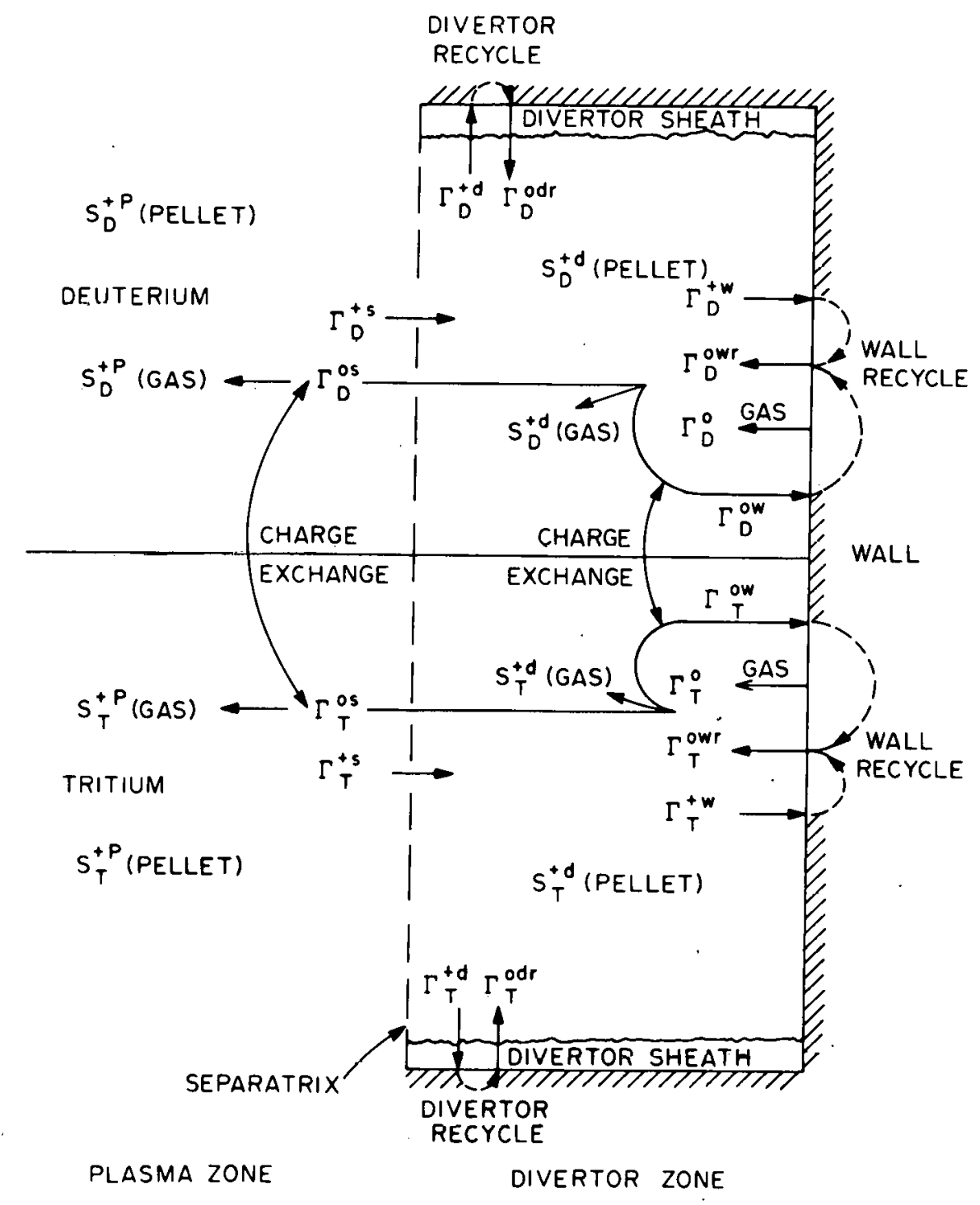

Fig. 1. 


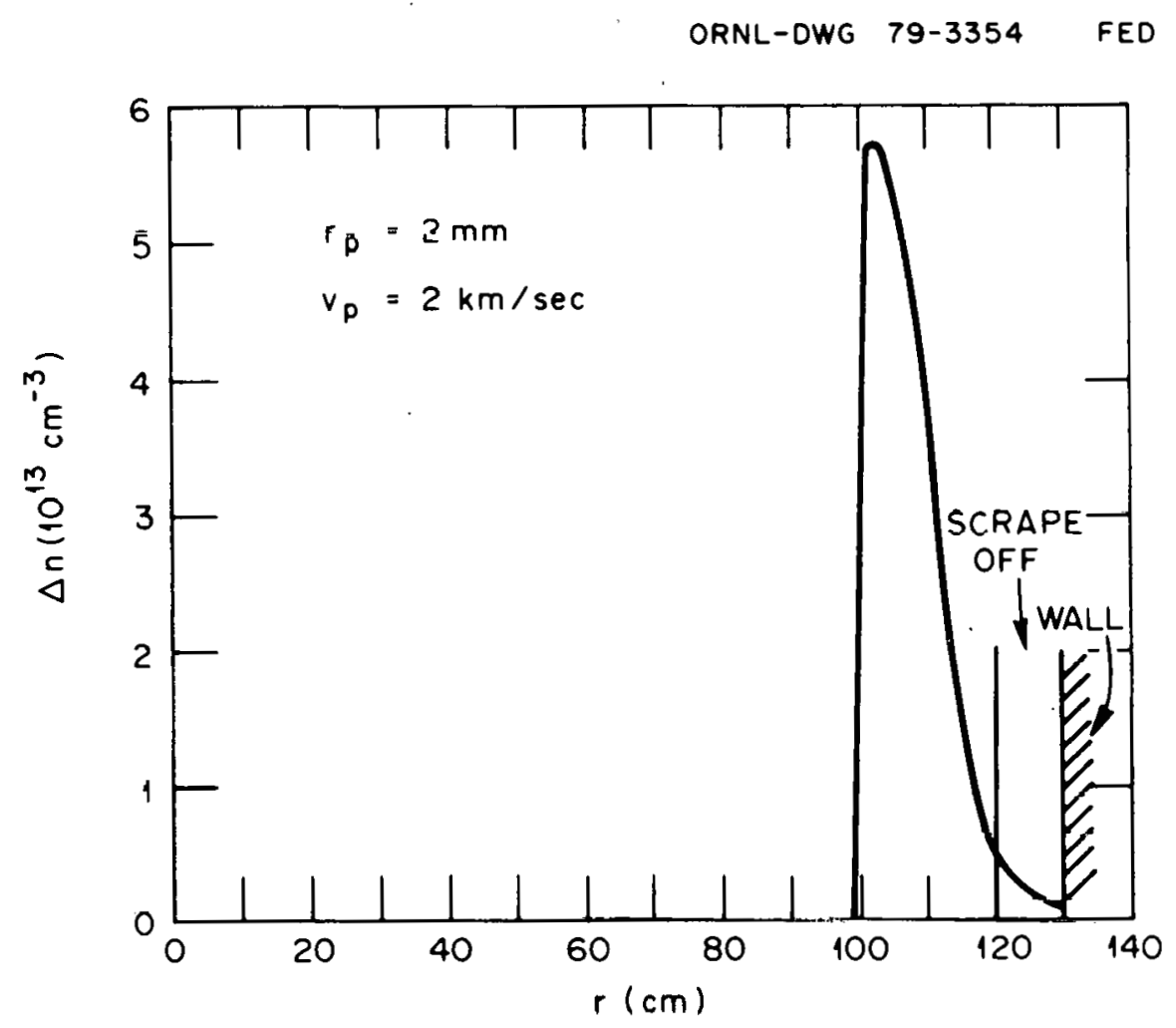

Fig. 2. 
0

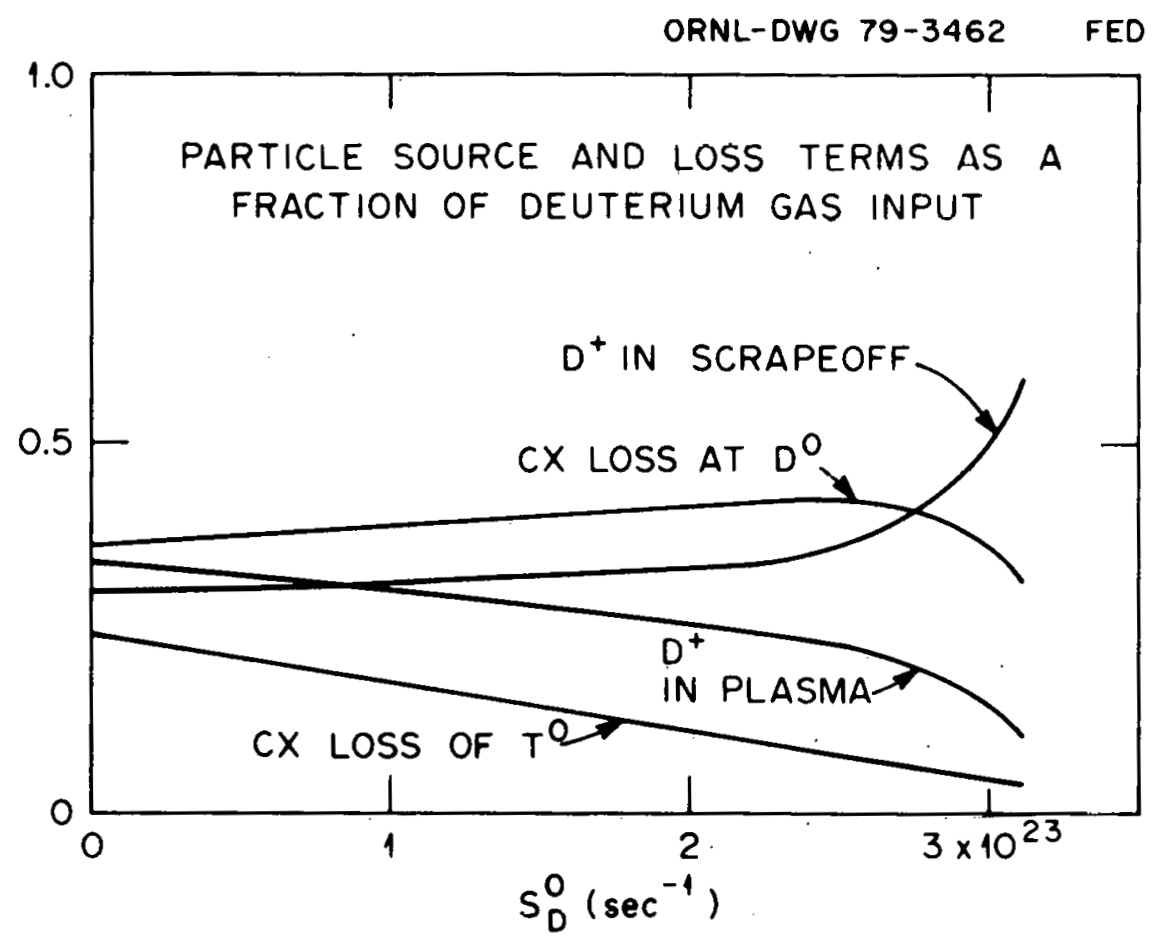

Fig. 3. 


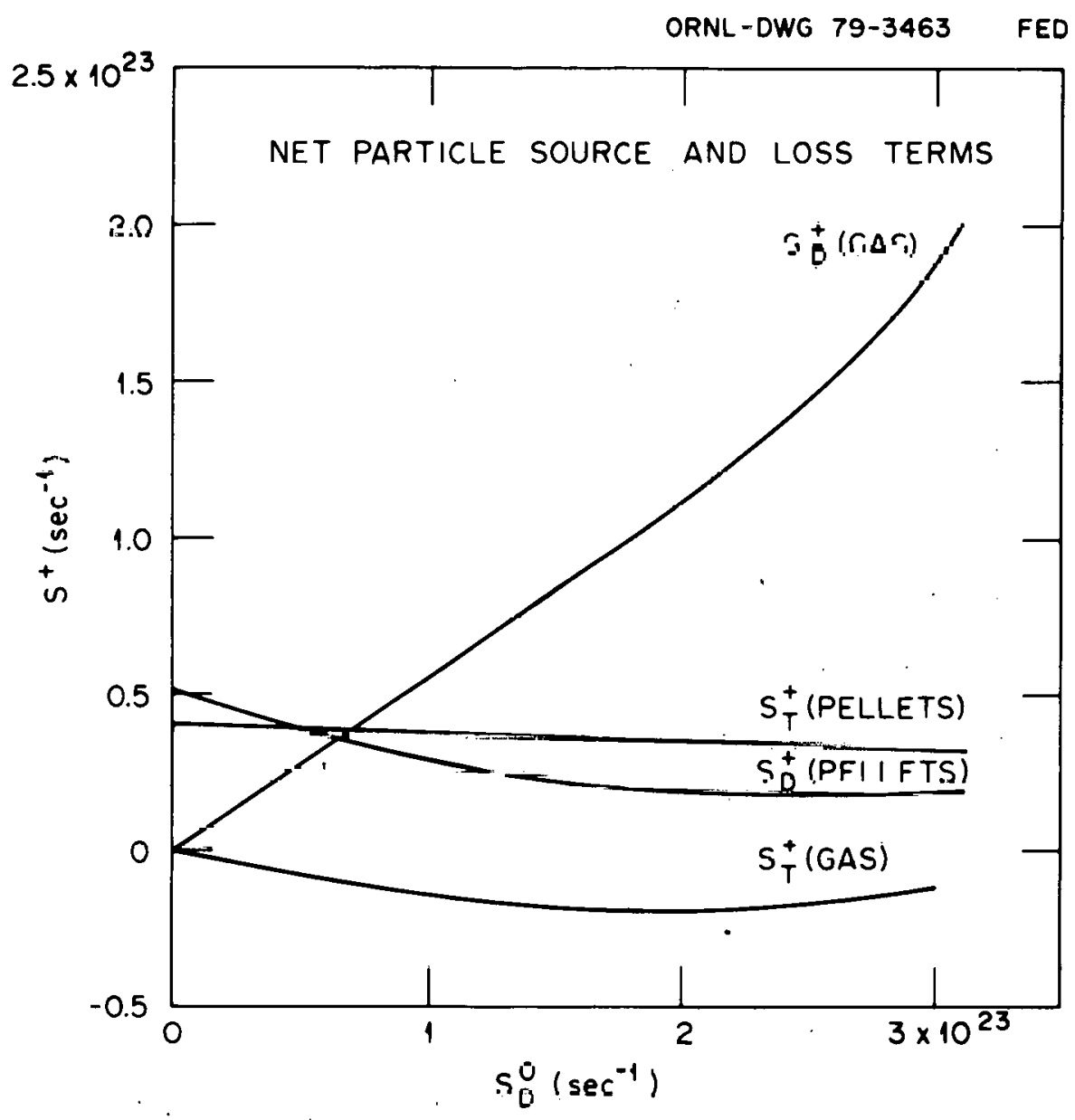

Fig. 4.

$n$

ᄂ 


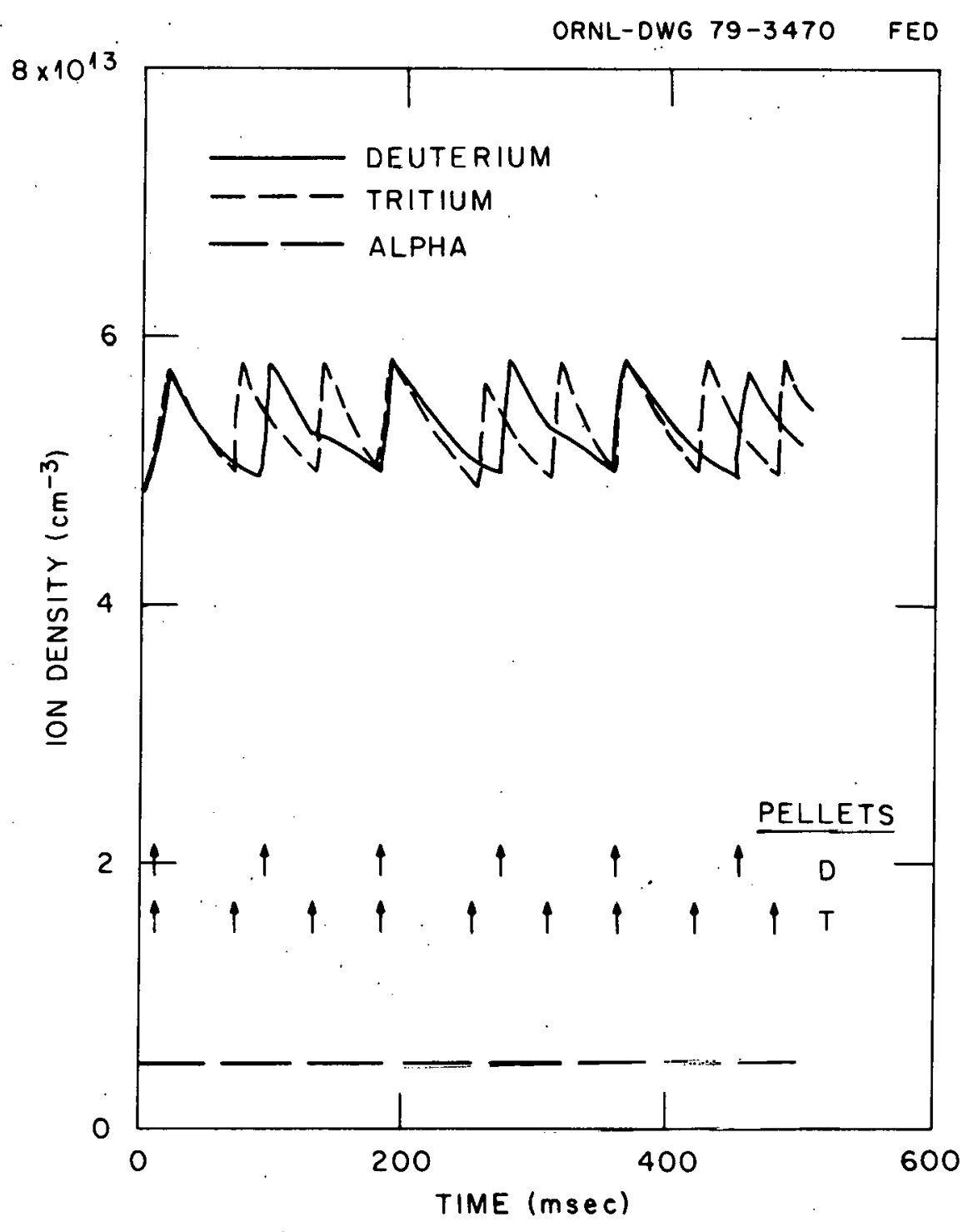

Fig. 5. 


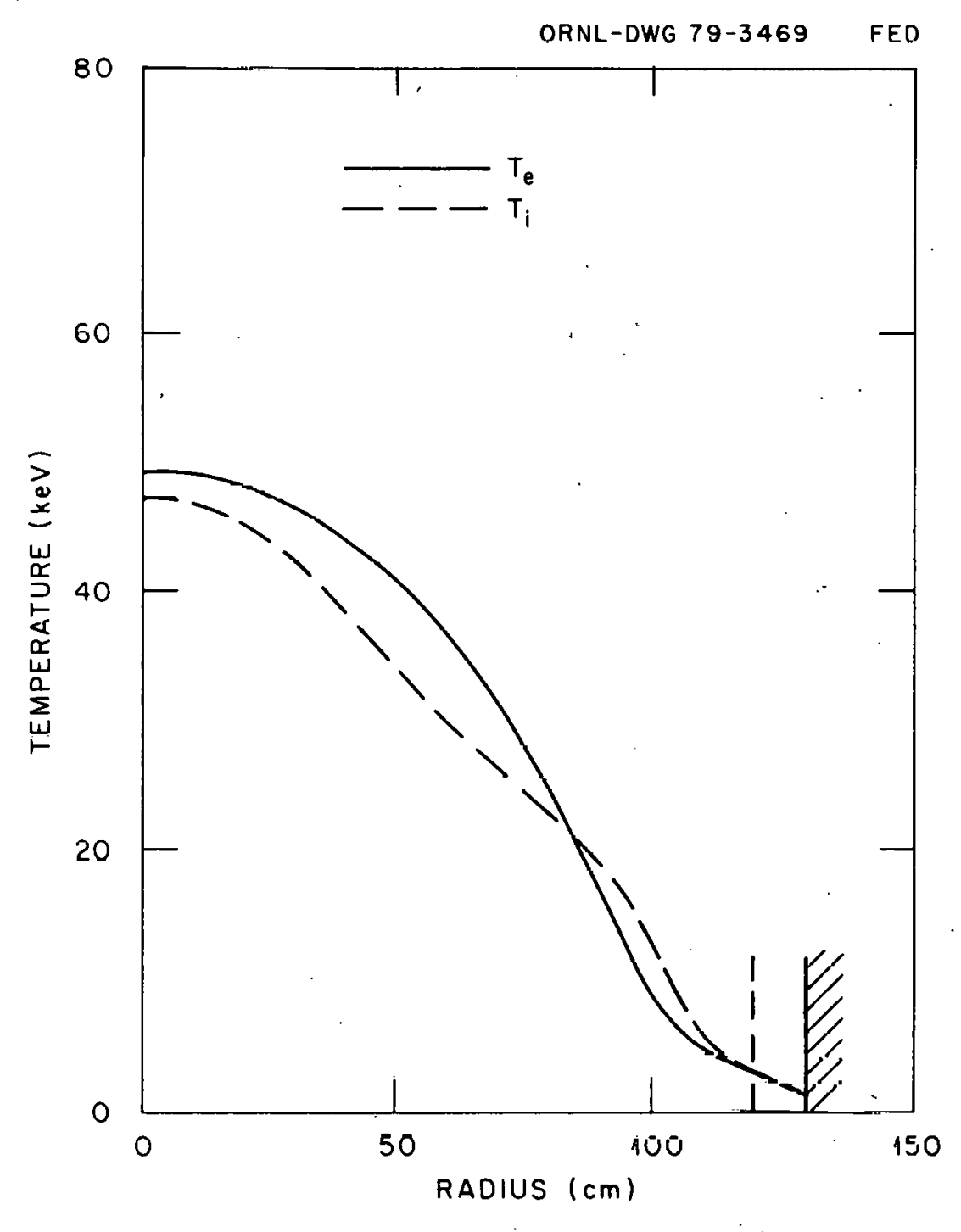

Fig. $\dot{b}$

0

b 


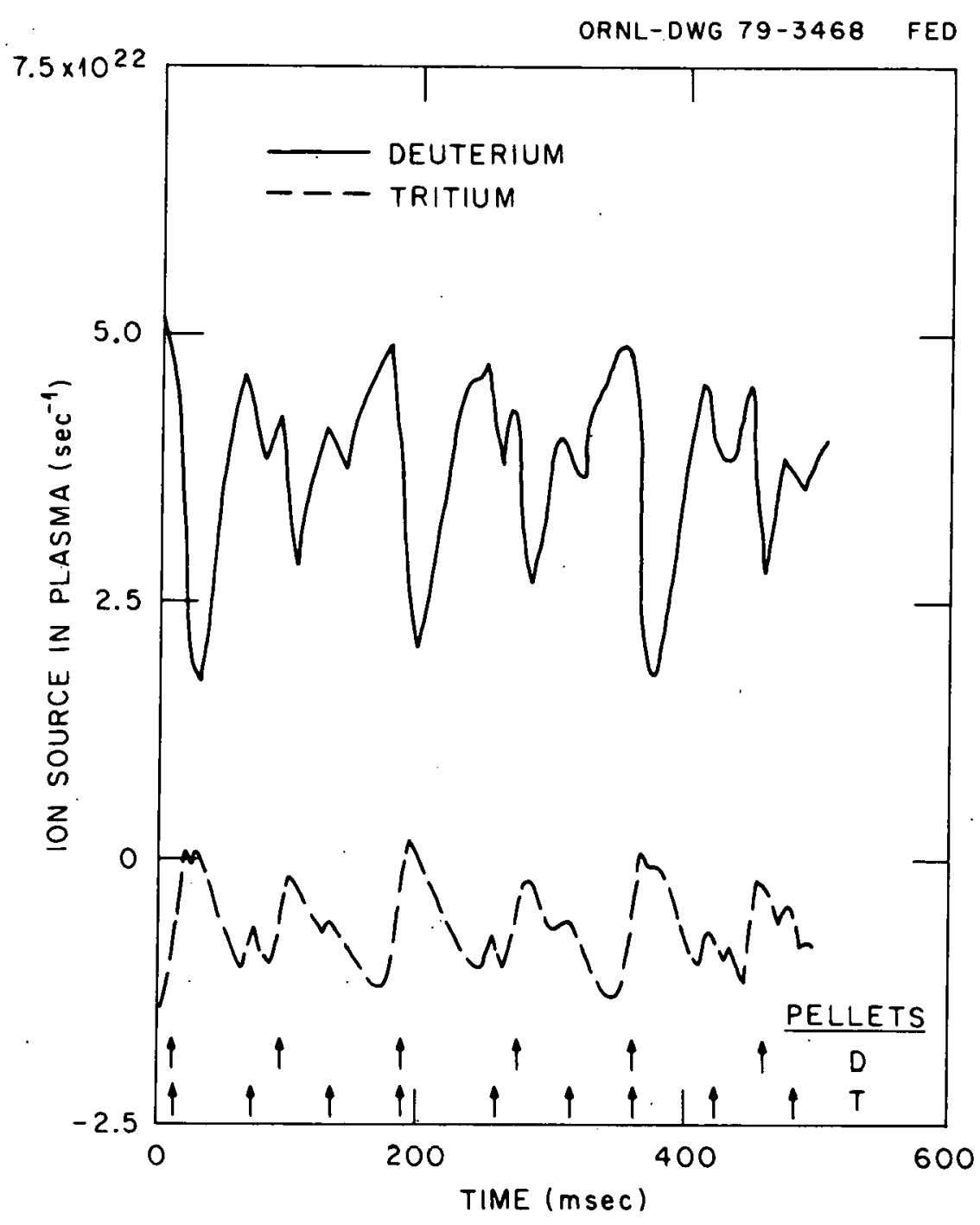

Fig. 7. 


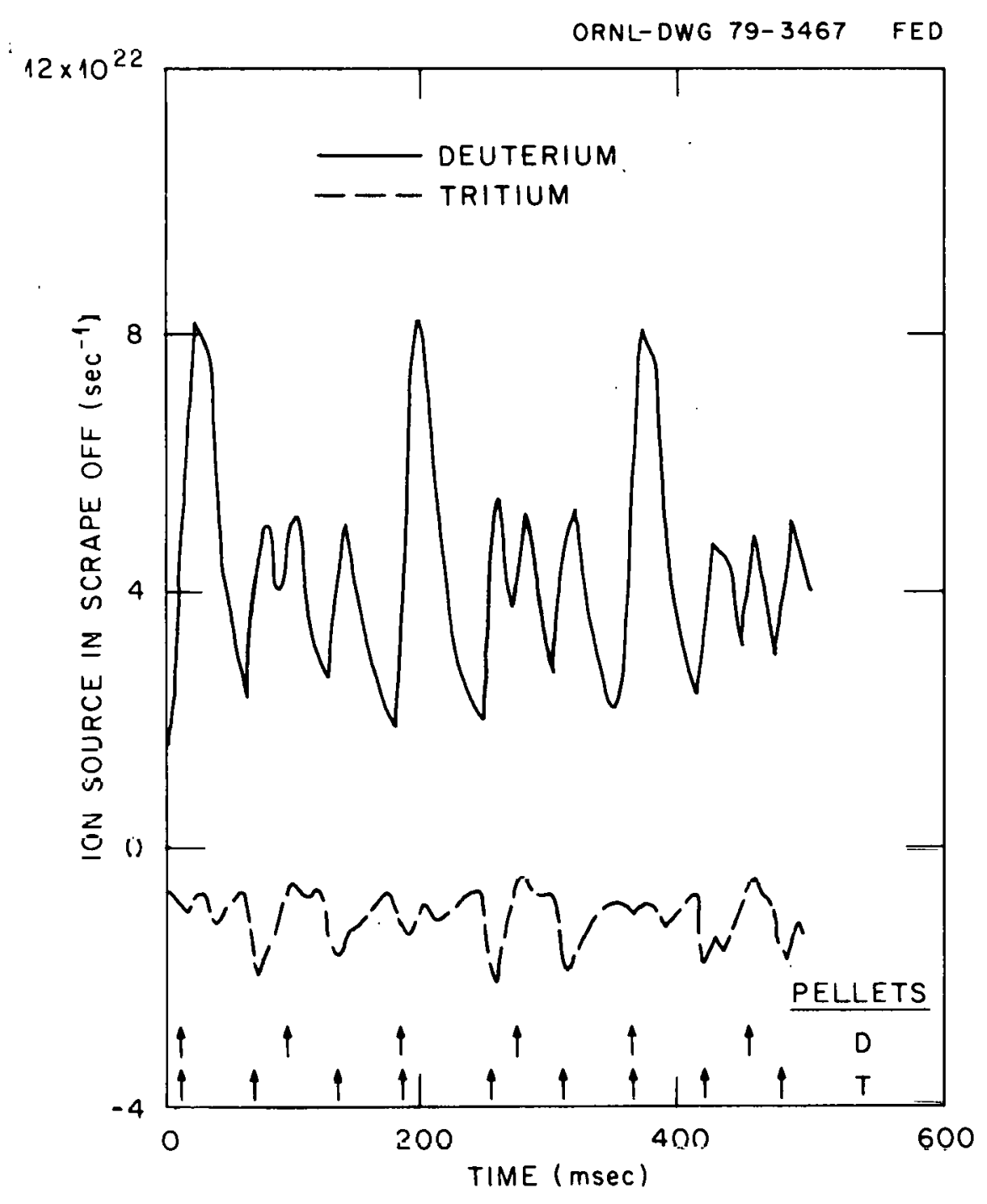

Fig. 8.

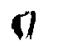




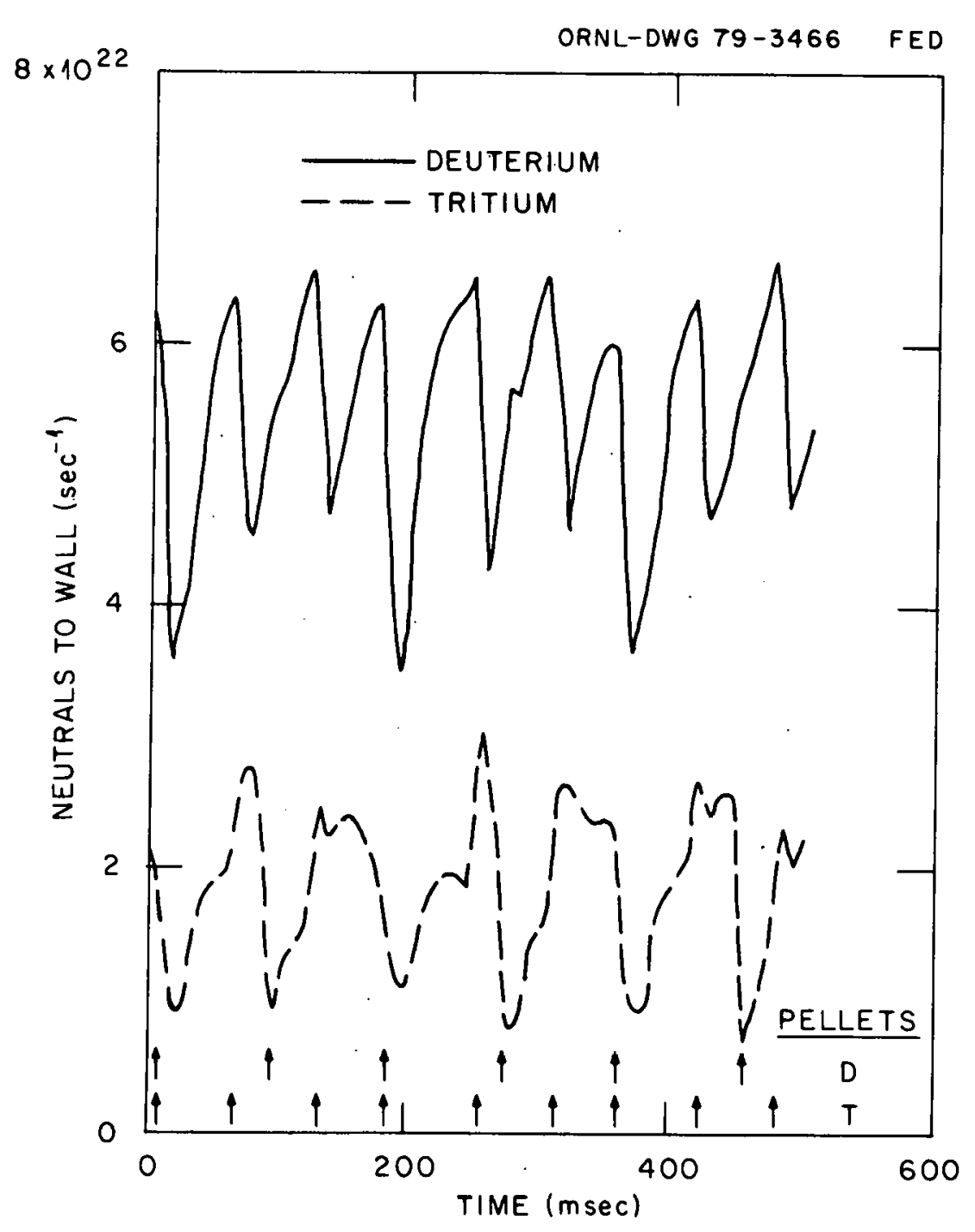

Fig. 9. 


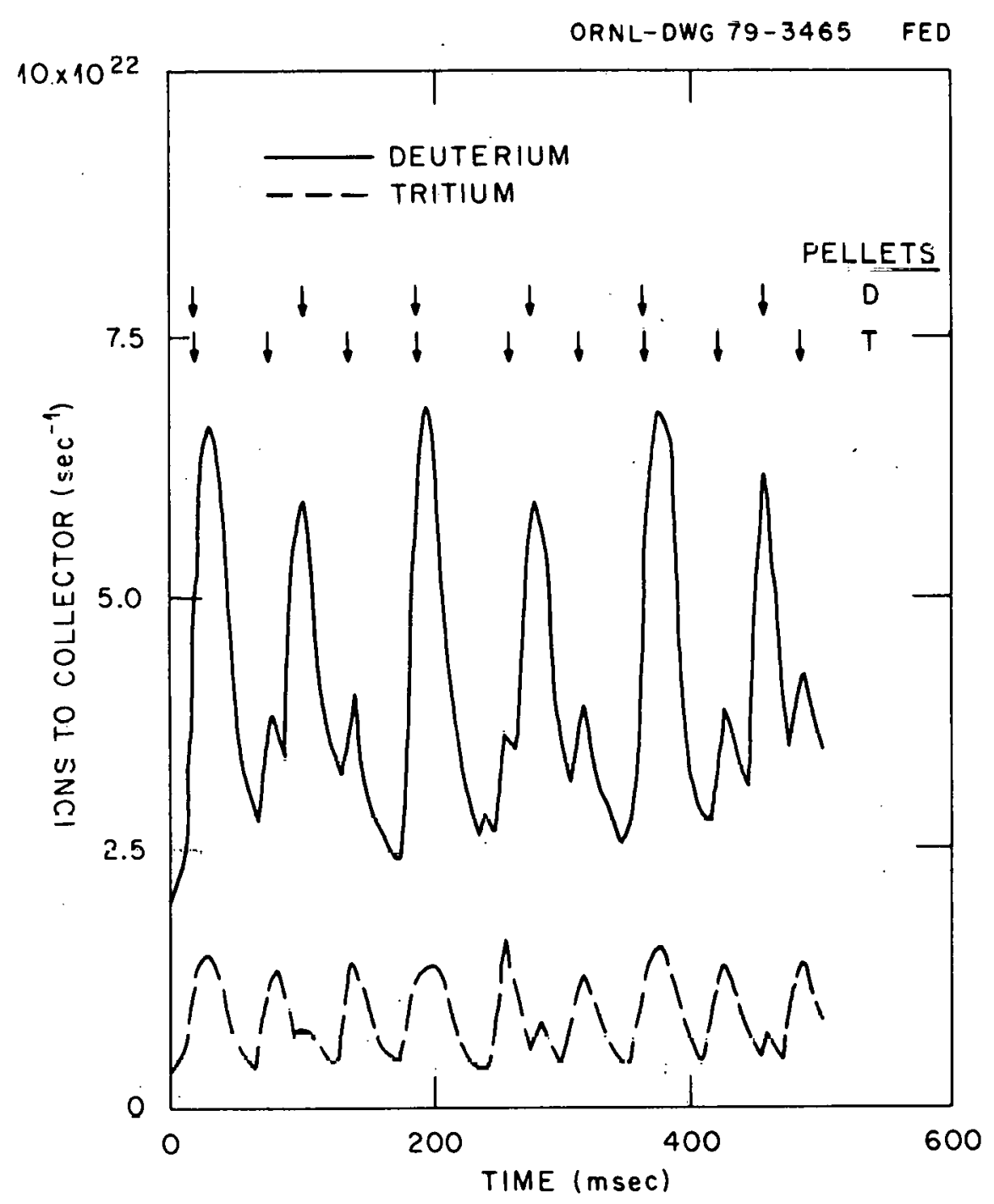

Fig. 10 . 


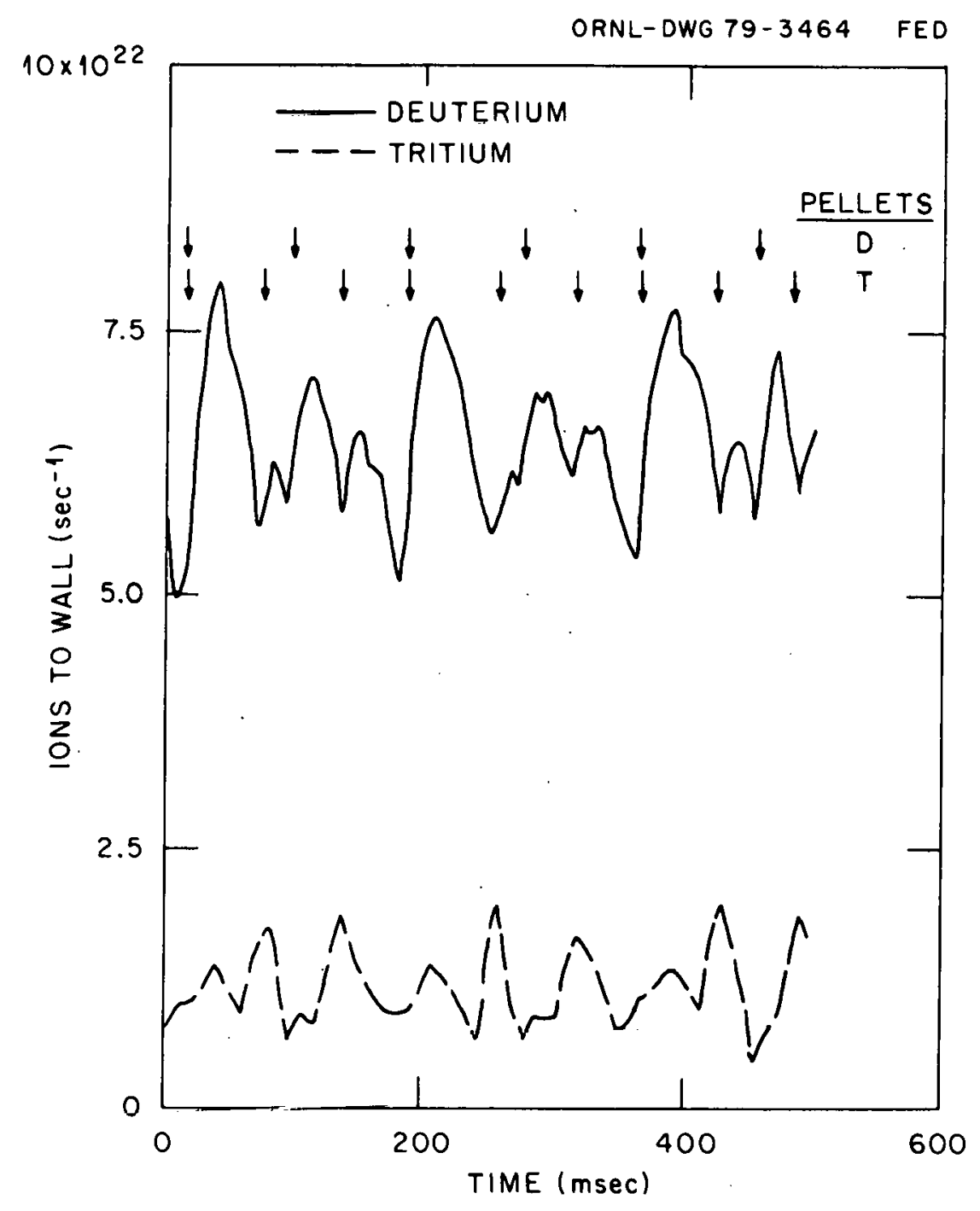

Fig, 11. 
THIS PAGE

\section{WAS INTENTIONALLY LEFT BLANK}




\author{
ORNL/TM-7124 \\ Dist. Category UC-20 a, d, g
}

\title{
INTERNAL DISTRIBUTION
}

1-5. S. E. Attenberger

6-19. W. A. Houlberg

20-24. H. C. Howe

25. J. Sheffield

26. D. Steiner

27-28. Laboratory Records

Department

29. Laboratory Records, ORNL-RC
30. Document Reference Section

31-32. Central Research Library

33. Fusion Energy Division

Library

34-35. Fusion Energy Division

Communications Center

36. ORNL Patent Office

\section{EXTERNAL DISTRIBUTION}

37. D. J. Anthony, Manager, Advanced Energy Systems Programs Department, General Electric Company, 1 River Road, Building 23, Room 290, Schenectady, NY 12345

38. Bibliothek, Institute for Plasma Physics, 8046 Garching bei München, Federal Republic of Germany.

39. Bibliothèque, Service du Confinement des Plasmas, C.E.A., B.P. No. 6, 92, Fontenay-aux-Roses (Seine), France

40. J. D. Callen, Department of Nuclear Engineering, University of Wisconsin, Madison, WI 53706

41. Prf. F. F. Cap, A 6020 Innsbruck, Innerebnerstr 40, Austria, Europe

42. Lung Cheung, Department of Electronics, University Science Center, The Chinese University of Hong Kong, Shatin, N.T., Hong, Kong

43. J. F. Clarke, Deputy Director, Office of Fusion Energy, Department of Energy, Mail Stop G-234, Washington, DC 20545

44. R. W. Conn, Department of Nuclear Engineering, University of Wisconsin, Madison, WI 53706

45. CTR Library, c/o A. F. Haught, United Technologies Research Laboratory, East Hartford, CT 06108

46. CTR Reading Room, c/o A. N. Kaufman, Department of Physics, University of California, Berkeley, CA 94720

47. J. N. Davidson, School of Nuclear Engineering, Georgia Institute of Technology, Atlanta, GA 30332

48. Documentation S.I.G.N., Département de 1a Physique du Plasma et de la Fusion Controlée, Association EURATOM-CEA sur la Fusion, Centre d'Études Nucléaires, B.P. 85 Centre du Tri, 38041 Grenoble, Cedex, France

49. W. R. Ellis, Office of Fusion Energy, Department of Energy, Mail Stop G-234, Washington, DC 20545

50. G. A. Emmert, Department of Nuclear Engineering, University of Wisconsin, Madison, WI 53706

51. H. K. Forsen, Exxon Nuclear Company, Incorporated, 777 106th Avenue, N.E., C-000777, Bellevue, WA 98004 
52. H. P. Furth, Princeton Plasma Physics Laboratory, Princeton University, P.0. Box 451, Princeton, NJ 08540

53. R. W. Gould, California Institute of Technology, Mail Stop 116-81, Pasadena, CA 91109

54. C. R. Head, Office of Fusion Energy, Department of Energy, Mail Stop G-234, Washington, DC 20545

55. R. L. Hirsch, General Manager for Exploratory Research, Exxon Research and Engineering Company, P.0. Box 101, Florham Park, NJ 07932

56. R. A. Huse, Manager, Research and Development Department, Public Service Electric and Gas Company, 80 Park Place, Newark, NJ 07101

57. V. E. Ivanov, Physical-Technical Institute of the Ukrainian SSR Academy of Sciences, 310108 Kharkov, U.S.S.R.

58. D. L. Jassby, Princeton Plasma Physics Laboratory, Princeton University, P.0. Box 451, Princeton, NJ 08540

59. A. Kadish, Office of Fusion Energy, Department of Energy, Mail Stop G-234, Washington, DC 20545

60. E. T. Karlson, Department of Technology, Box 534, S-75121 Uppsala, Sweden

61. Y. Kiwamoto, Research Institute for Energy Materials, Yokohama National University, Yokohama 232, Japan

62. R. N. Kostoff, Office of Energy Research, Department of Energy, Room 509, 401 First Street, N.W., Washington, DC 20545

63. L. M. Kovrizhnykh, Lebedev Institute of Physics, Academy of Sciences of the U.S.S.R., Leninsky Prospect 53, Moscow, U.S.S.R.

64. G. Laval, Groupe de Physique Théorique, École Polytechnique, 91 Palaiseau, Paris, France

65. Library, Centre de Recherches en Physique des Plasmas, 21 Avenue des Bains, 1007, Lausanne, Switzerland

66. Library, Culham Laboratory, United Kingdom Atomic Energy Authority, Abingdon, Oxun, OX14 3DB, Unlted Kingdom

67. Library, FOM-Institut voor PLasma-Fysica, Rijnhuizen, Jutphaas, Netherlands

68. Library, Institute for Plasma Physics, Nagoya University, Nagoya, Japan 464

69. Library, International Centre for Theoretical Physics, Trieste, Italy

70. Library, Laboratorio Gas Ionizzati, Frascati, Italy

71. J. G. Lominadze, Academy of Sciences of the Georgian S.S.R., 8 Dzerzhinski St., 38004, Tbilisi, U.S.S.R.

72. 0. P. Manley, Office of Fusion Energy, Department of Energy, Mail Stop G-234, Washington, DC 2ub4b

73. D. G. McAlees, Exxon Nuclear Company, Incorporated, 777 106th Avenue, N.E., Bellevue, WA 98004

74. J. E. McCune, School of Engineering, Department of Aeronautics and Ástronautics, Bldg. 37-391, Massachusetts Institute of Technology, Cambridge, MA 02139

75. A. T. Mense, Subcommittee on Energy Research and Production, B-374, Rayburn House Office Building, Washington, DC 20515

76. C. Mercier, Service du Théorie des Plasmas, Centre d'Études Nucléaires, Fontenay-aux-Roses (Seine), France 
77. M. Murphy, Office of Fusion Energy, Department of Energy, Mail Stop G-234, Washington, DC 20545

78. D. B. Nelson, Office of Fusion Energy, Department of Energy, Mail Stop G-234, Washington, DC 20545

79. K. Nishikawa, Institute for Fusion Thenry, Hiroshima University, Higashisendamachi, Hiroshima, Japan

80. B. Outten, Jr., Western Metal Products Company, 1300 Weber Street, Orlando, FL 32803

81. R. E. Papsco, Grumman Aerospace Corporation, 101 College Rnad, Princeton, NJ 08540

82. O. Petrus, Supervisor, C.T.R., Theory Group, Plasma Physics Laboratory, "Alexandru Ion Cuza," University, Iasi, Romania, 6600

83. D. Pfirsch, Institute for Plasma Physics, 8046 Garching bei München, Federa1 Republic of Germany

84. Plasma Physics Library, c/o P. Rosenau, Department of Mechanical Engineering, Technion-Israel, Institute of Technology, Haifa, Israel

85. Plasma Physics Group, Department of Engineering Physics, Australian National University, P.O. Box 4, Canberra A.C.T. 2600 , Australia

86. A. Rogister, Institute for Plasma Physics, KFA, Postfach 1913, D-5170, Jülich 1, Federal Republic of Germany

87. W. Sadowski, Office of Fusion Energy, Department of Energy, Mail Stop G-234, Washington, DC 20545

88. V. D. Shafranov, I. V. Kurchatov Institute of Atomic Energy, 46, Ulitsa Kurchatova, P.0. Box 3402, Moscow, U.S.S.R.

89. Y. S. Sigov, Institute of Applied Mathematics of the U.S.S.R. Academy of Sciences, Miuskaya, Sq. 4, Moscow A-47, U.S.S.R.

90. W. M. Stacey, Jr., School of Nuclear Engineering, Georgia Institute of Technology, Atlanta, GA 30332

91. L. D. Stewart, Princeton Plasma Physics Laboratory, P.0. Box 451, Princeton, NJ 08540

92. J. B. Taylor, Culham Laboratory, United Kingdom Atomic Energy Authority, Abingdon, Oxon, 0x14 3DB, United Kingdom

93. V. I. Tereshin, Yhysico-Technical Institute of the Ukrainian SSR Academy of Sciences, Kharkov, 310108 Kharkov, U.S.S.R.

94. Thermonuclear Library, Japan Atomic Energy Research Institute, Tokai, Naka, Ibaraki, Japan

95. Prf. N. L. Tsintsadze, Institute of Physics, Georgian Academy of Sciences, Guramishvili 6, Tbilissi-FF, U.S.S.R.

96. K. Uo, Plasma Physics Laboratory, Kyoto University, Gokasho, Uji, Kyoto, Japan

97. F. Verdaguer, Director, Division of Fusion, Junta de Energia Nuclear, Madrid 3, Spain

98. K. M. Zwilsky, Office of Fusion Energy, Department of Energy, Mail Stop G-234, Washington, DC 20545

99. Office of Assistant Manager, Energy Research and Development, Department of Energy, Oak Ridge Operations Office, Oak Ridge, TN 37830

100-318. Given distribution as shown 1n TIU-4500, Magnetic Fusion Energy (Distribution Category UC-20 a, d, g: Plasma Systems, Fusion Systems, and Theoretical Plasma Physics) 